using the American-European consensus criteria. Cumulative clinical data were collected at the moment of the last assessment. Clinical and laboratory parameters in SLE patients with SS (SLEwSS) were compared with those in SLE patients without SS (SLEwoSS).

Results: SS was identified in 516 SLE patients (14.4\%). Compared with the SLEwoSS group, patients with SLEwSS were significantly older, had a higher frequency of mucocutaneous manifestations, Raynaud's phenomenon, peripheral neuropathy, anti-Ro/SSA, anti-La/SSB, neoplasia, and older age at death, but had a significantly lower frequency of renal involvement, thrombocytopenia, antiDNA, anti- $\beta 2$-GPI IgM and complement consumption. Both groups displayed a clinically similar presentation of lymphadenopathy, systemic vasculitis, serositis, damage accrual, mortality, musculoskeletal and CNS manifestations.

\begin{tabular}{|l|c|c|c|}
\hline \multicolumn{1}{|c|}{ FEATURES } & $\begin{array}{c}\text { SLEwSS } \\
\mathbf{N = 5 1 6}\end{array}$ & $\begin{array}{c}\text { SLEwoSS } \\
\mathbf{N = 3 0 5 9}\end{array}$ & $\mathbf{p}$ \\
\hline Age, years \pm SD & $54.2 \pm 14.9$ & $45.6 \pm 14.5$ & $<0.001$ \\
\hline Age at SLE onset, years \pm SD & $38.6 \pm 15$ & $32.1 \pm 14$ & $<0.001$ \\
\hline Female & 97.5 & 89.1 & $<0.001$ \\
\hline Lymphadenopathy & 11.8 & 10.0 & 0.233 \\
\hline Photosensitivity & 65.0 & 57.2 & 0.002 \\
\hline Oral ulcers & 55.8 & 42.7 & $<0.001$ \\
\hline Alopecia & 36.3 & 32.0 & 0.069 \\
\hline Raynaud's Phenomenon & 39.9 & 32.7 & 0.001 \\
\hline Systemic vasculitis & 9.6 & 8.4 & 0.352 \\
\hline Arthritis & 75.0 & 76.5 & 0.467 \\
\hline Myositis & 4.0 & 3.4 & 0.515 \\
\hline Fibromyalgia & 13.9 & 5.1 & $<0.001$ \\
\hline Pleurisy & 22.7 & 22.4 & 0.893 \\
\hline Pulmonary fibrosis & 2.3 & 1.9 & 0.563 \\
\hline Renal manifestations & 18.3 & 32.7 & $<0.001$ \\
\hline Seizures & 6.3 & 6.6 & 0.805 \\
\hline Peripheral neuropathy & 5.4 & 2.9 & 0.004 \\
\hline Hemolytic anemia & 7.1 & 8.6 & 0.272 \\
\hline Leucopenia & 55.6 & 53.5 & 0.428 \\
\hline Thrombocytopenia & 15.5 & 20.8 & 0.007 \\
\hline Anti-Ro/SSA & 69.2 & 34.4 & $<0.001$ \\
\hline Anti-La/SSB & 48.1 & 14.4 & $<0.001$ \\
\hline Anti-Sm & 19.8 & 21.2 & 0.495 \\
\hline Anti-RNP & 23.2 & 25.2 & 0.317 \\
\hline Anti-DNA & 55.9 & 65.1 & $<0.001$ \\
\hline Anti- $\beta 2-$-GPI IgM & 8.6 & 14.5 & 0.006 \\
\hline Antiphospholipid syndrome & 13.0 & 14.0 & 0.520 \\
\hline Hypocomplementemia & 62.3 & 69.0 & 0.012 \\
\hline SLICC-ACR DI & $1.19 \pm 1.8$ & $1.03 \pm 1.7$ & 0.062 \\
\hline Neoplasia & 7.8 & 5.5 & 0.042 \\
\hline Exitus & 7.2 & 6.0 & 0.324 \\
\hline Age at death, years \pm SD & $67.3 \pm 14.4$ & $54.2 \pm 18.0$ & $<0.001$ \\
\hline SLEwSS: Systemic lupus erythematosus with Sjögren's syndrome. SLEwoSS: Systemic \\
\hline lupus erythematosus without Sjogren's syndrome. SuCC-ACR DI: Systemic Lupus \\
\hline International Collaborating Clinics/American College of Rheumatology Damage Index. \\
\hline \multicolumn{1}{|c|}{ Except where indicated otherwise, values are the percentage. } \\
\hline & & & \\
\hline
\end{tabular}

Conclusions: SLEwSS appears to constitute a subgroup of SLE patients with distinct clinical and serologic features, in whom SS is expressed as an overlapping entity. A particular cluster of clinical variables, namely, mucocutaneous manifestations, Raynaud's phenomenon, peripheral neuropathy, renal involvement and thrombocytopenia, was found to be important overall for discriminating SLE patients with or without SS. SLEwSS patients constitute a subgroup of patients with SLE characterised by milder lupus: older age at death, similar rates of mortality and SLICC-ACR damage index, less renal and immunological manifestations. Disclosure of Interest: None declared

DOI: 10.1136/annrheumdis-2018-eular.6123

\section{FRI0369 PREGNANCY OUTCOMES IN WOMEN WITH ANTIPHOSPHOLIPID ANTIBODIES: INTERIM RESULTS FROM A SINGLE CENTRE COHORT STUDY}

K. Schreiber ${ }^{1,2}$, M. Frishman ${ }^{1}$, M.J. Cuadrado ${ }^{3}$, K. Breen ${ }^{1}$, S. Robinson ${ }^{1}$, B. J. Hunt ${ }^{1} .{ }^{1}$ Department of Thrombosis and Haemophilia, Guy's and St Thomas' Hospital, London, UK; ${ }^{2}$ Copenhagen Lupus and Vasculitis Clinic, Center for Rheumatology and Spine Diseases, Copenhagen University Hospital, Rigshospitalet, Copenhagen, Denmark; ${ }^{3}$ Department of Rheumatology, Guy's and St Thomas' NHS Foundation Trust, London, UK

Background: Persisting antiphospholipid antibodies (aPL) are associated with adverse obstetric events including recurrent miscarriage, late fetal loss or early delivery due to pre-eclampsia or placental insufficiency (obstetric APS) and also thrombosis. We are a tertiary referral centre for those with aPL, and have a management protocol for women with aPL during pregnancy and the puerperium with the aim of preventing obstetric complications and maternal thrombosis.

Objectives: To report the fetal and maternal outcomes from a single centre cohort of 511 pregnancies in 372 women over a period of eight years.

Methods: This is an ongoing retrospective observational study registered as an audit. Data was collected from clinic lists attending the pregnancy clinic at the Thrombosis centre of St. Thomas' Hospital in London, UK between Jan 2010 to December 2017. Women persistently positive for aPL were included if pregnancy outcome data was available.

Results: 511 pregnancies in 372 women were included in the study (table 1). The overall live birth rate was $78.9 \%$. Pregnancy outcomes are outlined in table 2 .

Abstract FRI0369 - Table 1. Demographics

\begin{tabular}{lc}
\hline Age in years, median (range) & $35(18-50)$ \\
\hline Ethnicity (white:black:asian:other:not specified) & $(186(50 \%): 17(5 \%): 35(9 \%): 94(25 \%): 40$
\end{tabular}

Antiphospholipid antibody profile at

$(11 \%))$

\section{diagnosis}

Lupus anticoagulant, $\mathrm{n}(\%)$ (dAPTT:DRVVT:

TSVT)

Anticardiolipin $\lg G$ and $\lg M, n(\%)$

$\beta 2$-glycoprotein-I IgG and IgM, $\mathrm{n}(\%)$

APS history

Obstetric APS (any), $\mathrm{n}(\%)$

Obstetric APS (1 st trimester loss), $n$ (\%)

Obstetric APS (2nd trimester loss), n (\%)

Fetal death (>24 weeks), $\mathrm{n}(\%)$

Intrauterine growth restriction, $\mathrm{n}(\%)$

Pre-eclampsia, $n$ (\%)

Thrombotic APS (any), n (\%)

Autoimmune profile

ANA:ENA:dsDNA, $n(\%)$

$261(70 \%)(183: 144: 27)$

$119(40 \%)$ and $144(39 \%)$

$16(4 \%)$ and $27(7 \%)$

$$
\begin{gathered}
125(34 \%) \\
74(20 \%) \\
35(9 \%) \\
19(5 \%) \\
30(8 \%) \\
19(5 \%) \\
106(29 \%) \\
(n=511)
\end{gathered}
$$

\begin{tabular}{|c|c|}
\hline Pregnancy outcomes & Total pregnancies, no511 \\
\hline \multicolumn{2}{|l|}{ Treatment during pregnancy } \\
\hline Appitin, $75 \mathrm{mg}$ doily, $n|\mathrm{~s}|$ & $500(24 x)$ \\
\hline Low molectres weigh heporin, $n(5)$ & $381(72 x)$ \\
\hline Npprin + Megarin & $357(200 x)$ \\
\hline Aspatin - Meperih - HCQ & $6(17 \%)$ \\
\hline Hydroxychloroquine, in: & $158(300 x)$ \\
\hline Neathioptine, n(6) & $521.006)$ \\
\hline Antihnoertencives, a(x) & $17(3 \times)$ \\
\hline Ssetoiles, $n(x)$ & $123(23 \times)$ \\
\hline Steroiles dose in me, menn 150, rangel & $\operatorname{tas}(-1 / 5,4,2-40)$ \\
\hline O12 supplenents,,$\{x\}$ & $13(3 \times)$ \\
\hline VeA priar to pegenanny, n(X) & $67(13 x)$ \\
\hline IVF treatment an $\left|x_{1}\right|$ & 69113\%) \\
\hline Pregnancy outcomes & (n=511) \\
\hline Lwe bints, $n(x)$ & $\cos (29 x)$ \\
\hline Twin pregnoncies & $23(36)$ \\
\hline Contational age at delivendweeks, reen|5D, angel & $33(0 \% / 2,25-80)$ \\
\hline Arthweigh $2550 \mathrm{~g}$ & $35(100 x)$ \\
\hline Brtheizh: $<5508$ & $\lambda(1 \mathrm{x})$ \\
\hline Brttweizht in gram, mean 150 , rongel & $3170+-1-315,575-53001$ \\
\hline Pregnancy bs, <10 wetes, n(x) & $70(126 x)$ \\
\hline 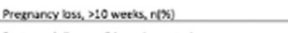 & $27(5 x)$ \\
\hline 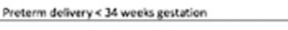 & $23(2.5 \%)$ \\
\hline Preteen deintery< 37 weés sestexion & 521:06) \\
\hline 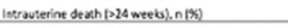 & $7(1 \times)$ \\
\hline Preedimpasis & $23(4 \times)$ \\
\hline Throrttosis durikg peregnance, $n|x\rangle$ & $9(4) \times)$ \\
\hline Caetarean sectioe, n ins) & $268(336)$ \\
\hline
\end{tabular}

$141(39 \%): 94(26 \%): 19(5 \%): 56$ (15\%)

Key: ANA, antinuclear antibodies, APS, antiphospholipid syndrome; aPL, antiphospholipid antibodies; aAPPT, dilute Activated Partial Thromboplastin Time; dRVVT, dilute Russe Viper Venom Time; dsDNA, doublestranded DNA, ENA, Extractable nuclear antigens, TSVT, Taipan Snake Venom Time

Abstract FRI0369 - Table 2. Pregnancy outcomes

Conclusions: These results from the largest single centre cohort reported show that using our management protocol, nearly $80 \%$ of women with aPL had a successful pregnancy outcome.

Disclosure of Interest: None declared

DOI: 10.1136/annrheumdis-2018-eular.7252 